\title{
PORTFÓLIO INTEGRADO DE PROJETOS: IMPLANTAÇÃO DE PROCESSOS INSTITUCIONAIS EM UM BANCO
}

\author{
INTEGRATED PROJECT PORTFOLIO: IMPLEMENTATION OF INSTITUTIONAL \\ PROCESSES IN A BANK
}

\author{
Danielle Cruz Paiva \\ Mestre em Administração - Gestão de Projetos \\ Universidade Nove de Julho - UNINOVE \\ São Paulo, SP - Brasil \\ danipaiva@hotmail.com \\ Roque Rabechini Junior \\ Pós-doutor em Administração \\ Universidade de São Paulo - FEA/USP \\ São Paulo, SP - Brasil \\ rabechinijr@gmail.com
}

Resumo: Em um cenário de crescente investimento em projetos, estudos acerca dos processos de gerenciamento de portfólio de projetos apoiam a execução da estratégia organizacional. O objetivo deste relato técnico é apresentar como uma instituição bancária integrou seus vários portfólios de projetos setoriais, por meio da implementação de processos institucionais de gerenciamento de portfólio que favorecem o atingimento dos objetivos estratégicos organizacionais. Em relação ao método, a situação problema e intervenção são analisadas em abordagem qualitativa, por meio de estudo de caso, embasado por entrevistas, análise documental e observação. Como principal resultado ressalta-se que o portfólio integrado de projetos aprimorou o alinhamento estratégico da organização. Sendo que os processos de identificação, avaliação e seleção do portfólio foram formalizados, promovendo a integração entre as unidades organizacionais e um melhor balanceamento entre objetivos estratégicos de curto e longo prazo no portfólio. Neste sentido, este relato colabora com a literatura de gerenciamento de portfólio de projetos, reforçando os conceitos da estruturação do portfólio. A contribuição para a prática profissional se dá ao retratar processos do gerenciamento de portfólio, que podem ser adotados como benchmark por outras organizações, além de apresentar os direcionadores estratégicos adotados para balanceamento do portfólio de projetos de instituição financeira.

Palavras-chave: Gerenciamento de projetos. Gerenciamento de portfólio de projetos. Seleção de projetos. Balanceamento de portfólio. Alinhamento estratégico.

\begin{abstract}
In the context of increasing project investments, studies regarding the process of project portfolio management contribute to the execution of organizational strategy. The aim of this technical report is to show how a banking institution has integrated its various sectorial portfolios, by implementing institutional processes for portfolio management that favor the achievement of organizational strategic objectives. Related to the method, the problem situation and intervention are qualitatively characterized through a case study, supported by interviews, document analysis, and observation. As the main result, the integrated project portfolio has improved strategic alignment in the organization. Project portfolio identification, evaluation, and selection were formalized, facilitating the integration of various business units and improving how short and long-term strategic goals were balanced in the portfolio. As a theoretical contribution, this paper adds to project portfolio management literature, strengthening the concepts of portfolio structuring. It also contributes to practice by characterizing how project portfolio management was improved, and which strategic drivers were chosen to balance the portfolio, in the banking institution, with information that may be useful as a benchmark.
\end{abstract}

Keywords: Project management. Project portfolio management. Project selection. Portfolio balancing. Strategic alignment.

\section{Cite como}

American Psychological Association (APA)

Paiva, D. C., \& Rabechini Junior, R. (2021, jul./dez.). Portfólio integrado de projetos: implantação de processos institucionais em um banco. Revista Inovação, Projetos e Tecnologias - IPTEC, São Paulo, 9(2), 184-196. https://doi.org/10.5585/iptec.v9i2.19230. 


\section{Introdução}

O Produto Interno Bruto (PIB) brasileiro relativo à indústria de serviços cresceu $9 \%$ entre 2010 e 2017 (World Development Indicators | The World Bank, 2019), capitaneado pelo bom desempenho das instituições financeiras. No mesmo sentido, pesquisa da Federação Brasileira de Bancos (FEBRABAN, 2018) destaca o aumento dos investimentos em softwares como instrumento para a concretização de demandas de negócios. Portanto, depreende-se que as instituições financeiras brasileiras elevaram seus investimentos em projetos de negócios no período.

Num contexto de mais investimentos em projetos de negócios, o gerenciamento de portfólio de projetos se apresenta como ferramenta para aprimorar o desempenho empresarial (Padovani \& Carvalho, 2016). Embasando este conceito, o PMI (2017) explica que o gerenciamento de portfólio de projetos organiza projetos não interdependentes ou relacionados, que buscam objetivos estratégicos comuns. Da mesma forma, o portfólio de projetos é tido como instrumental para a implantação da estratégia organizacional (Bredillet, Tywoniak, \& Tootoonchy, 2018).

Contudo, falta ainda consenso sobre quais são os processos fundamentais para o gerenciamento do portfólio de projeto (Padovani \& Carvalho, 2016). Neste contexto, alguns autores consideram os processos de seleção e priorização de projetos relevantes para o gerenciamento do portfólio de projetos (Archer \& Ghasemzadeh, 1999; Meskendahl, 2010; Padovani \& Carvalho, 2016). Podendo estar relacionados com a orientação estratégica e o sucesso da organização (Meskendahl, 2010).

Tendo em vista a relevância do gerenciamento do portfólio de projetos para o desempenho empresarial, define-se a questão de pesquisa deste trabalho técnico. Como os processos de gerenciamento de portfólio de projetos foram aprimorados, a fim de favorecerem o atingimento dos objetivos estratégicos organizacionais em uma instituição bancária?

Assim, o objetivo deste relato técnico é apresentar como uma instituição bancária integrou seus vários portfólios de projetos setoriais, por meio da implementação de processos institucionais de gerenciamento de portfólio que favorecem o atingimento dos objetivos estratégicos organizacionais. Inicialmente apresentado em congresso científico (Paiva \& Rabechini Jr., 2020), as considerações de revisores e mediadores foram acrescentadas ao relato técnico original.

A análise da situação problema adota abordagem qualitativa, por meio de estudo de caso, na qual o pesquisador estuda uma situação problema com o objetivo de responder 
perguntas do tipo "como" (Yin, 2017). Análise documental, observação e entrevistas com profissionais envolvidos na implantação do projeto permitiram triangular informações (Yin, 2017). Desta maneira, foram caracterizadas as melhorias no gerenciamento do portfólio de projetos de negócios da instituição bancária.

Na situação inicial, cada unidade de negócios do banco definia intuitivamente lista de projetos de negócios prioritários, com o objetivo de refletir a estratégia do respectivo segmento. Caracterizavam-se, desta forma, portfólios de projetos setoriais. No entanto, nesta configuração não eram consideradas as interferências em desenvolvimento de software que a execução de um projeto de negócio de crédito, por exemplo, poderia produzir em projetos de negócio de conta corrente ou de financiamentos rotativos. Como resultado, o planejamento do portfólio era comprometido.

Após a implantação das melhorias, a seleção de projetos de negócios para o portfólio passou a acontecer de forma estruturada. As várias unidades de negócios passaram a qualificar seus projetos de acordo com indicadores pré-definidos. Desta maneira, projetos de todos os segmentos poderiam competir entre si pelos recursos organizacionais, num portfólio de projetos de negócios integrado.

Para caracterizar o portfólio de projetos de negócios integrado, este relato técnico se estruturará em algumas seções, conforme protocolo para elaboração de produções técnicas de Biancolino, Kniess, Maccari e Rabechini (2012). A seção 2 apresenta o referencial teórico tratando do gerenciamento de portfólio de projetos, com foco nas funções de estruturação. Na sequência, a seção 3 descreve o método de estudo de caso empregado nesta produção técnica, enquanto a seção 4 relata o contexto da situação problema caracterizada pelos portfólios de projetos setoriais. Ainda, a seção 5 descreve como ocorreu evolução do gerenciamento de portfólio na instituição bancária, destacando os novos processos de gerenciamento que passaram a compor o portfólio de projetos integrado, enquanto a seção 6 analisa os resultados deste trabalho. Concluindo, a seção 7 destaca as principais conclusões do presente relato técnico.

\section{Referencial teórico}

\subsection{Gerenciamento de portfólio com foco nas etapas de estruturação}

O gerenciamento de portfólio de projetos engloba projetos que não são necessariamente dependentes ou relacionados entre eles, mas buscam objetivos estratégicos comuns (PMI, 2017). Iniciando por Wheelwright e Clark (1992) que conceituaram o "plano agregado de 
projeto", vários autores se dedicaram ao estudo do gerenciamento de portfólio de projetos (Bredillet et al., 2018; Meskendahl, 2010; Padovani \& Carvalho, 2016). No contexto organizacional, o portfólio de projetos atua como instrumento tático da estratégia (Bredillet et al., 2018), do mesmo modo que o trabalho dos profissionais de projetos molda sua execução ao solucionar problemas emergentes (Löwstedt, Räisänen, \& Leiringer, 2018).

O gerenciamento de portfólio compreende uma coleção de processos organizacionais, como a seleção de projetos, a alocação dos recursos organizacionais, o monitoramento e o controle do portfólio (Carvalho, Lopes, \& Marzagão, 2013), apesar do pouco consenso sobre quais seriam estes processos fundamentais (Padovani \& Carvalho, 2016). Numa fase prévia à definição do portfólio, aparecem os processos de seleção, que devem verificar propostas de projetos e projetos em conclusão, para decidir quais são mais relevantes frente ao cenário interno e externo da corporação (Archer \& Ghasemzadeh, 1999).

Requerem previsões sobre as necessidades de recursos de cada iniciativa, bem como sobre os recursos organizacionais disponíveis - humanos, financeiros e de tempo (Archer \& Ghasemzadeh, 1999; Padovani \& Carvalho, 2016). Com estas informações, decide-se como melhor alocar os recursos (Padovani \& Carvalho, 2016). Nesta tomada de decisão, recomendase a participação de diversos stakeholders e o balanceamento de projetos que tragam benefícios diversos para a organização (Padovani \& Carvalho, 2016).

Usualmente, as decisões do portfólio de projetos são tomadas em um comitê que integra várias áreas corporativas, permitindo que critérios subjetivos sejam igualmente considerados (Archer \& Ghasemzadeh, 1999). Esta prática é reportada também em empresas de serviços, já que facilitam que os interesses da alta gestão das empresas sejam refletidos nas decisões do portfólio (Aas, Breunig, \& Hydle, 2017).

O gerenciamento de portfólio abrange ainda o monitoramento e o controle de sua execução (Carvalho et al., 2013). Neste contexto, o monitoramento da situação de cada projeto, em comunicação padronizada e regular com os stakeholders, permite a atuação preventiva dos gerentes de portfólio quando algum projeto dá sinais de alerta durante o ciclo de vida (Hopmere, Crawford, \& Harré, 2020). Considerando que muitas vezes os gerentes de portfólio são recipientes de grande volume desta comunicação padronizada, análises de tendências podem auxiliá-los na identificação de sinais de atenção iniciais que possam desencadear eventuais reflexos negativos, se não gerenciados (Hopmere et al., 2020).

Com base nas evidências de que investimentos para a estruturação do gerenciamento de portfólio de projetos rendem benefícios ao desempenho das organizações (Padovani \& Carvalho, 2016), retorna-se aos processos de seleção e priorização de projetos, que são o foco 
deste trabalho. Meskendahl (2010) os conceitua como funções periódicas de estruturação do portfólio, e identifica reflexos destas na orientação estratégica e no desempenho da organização.

As funções de estruturação do portfólio devem respeitar quatro características-chave (Meskendahl, 2010). a) Garantir que o portfólio esteja alinhado com a orientação estratégica organizacional. b) Formalizar os processos de identificação, avaliação e seleção dos projetos do portfólio. c) Integrar as diversas áreas corporativas na tomada de decisão do portfólio. d) Garantir que o portfólio seja balanceado com projetos que reflitam objetivos organizacionais de curto e longo prazo (Meskendahl, 2010).

Com base nos conceitos teóricos relatados, este trabalho analisará o gerenciamento de portfólio de uma organização tendo em vista o construto proposto por Meskendahl (2010). Portanto, será demonstrado como uma instituição bancária integrou seus vários portfólios de projetos setoriais, por meio da implementação de processos institucionais de gerenciamento de portfólio que favorecem o atingimento dos objetivos estratégicos organizacionais.

\section{Metodologia}

Este relato técnico estrutura-se sobre o roteiro para produções técnicas proposto por Biancolino et al. (2012), que traça diretrizes para que conhecimentos práticos e profissionais sejam reportados, levando em consideração o respeito às normas para produções acadêmicas. Particularmente, este trabalho baseia-se em abordagem qualitativa, por meio de estudo de caso (Creswell \& Creswell, 2017). Tal método é tido como método preferido quando pesquisadores estudam uma situação de forma aprofundada, sem controle sobre os sujeitos em observação e com pouca delimitação entre o contexto em que o sujeito se insere e ele próprio (Yin, 2017).

Elaboração de síntese da literatura relacionada foi o ponto de partida da pesquisa. $\mathrm{Na}$ sequência, foram coletadas informações documentais primárias e registradas as observações do pesquisador. E, a seguir, profissionais que vivenciaram a evolução do gerenciamento de portfólio na instituição financeira foram entrevistados, cujos perfis estão caracterizados na Tabela 1. Assim, as várias fontes de informações foram analisadas por meio da análise de conteúdo, caracterizando tanto a situação-problema quanto a intervenção para a implantação do novo portfólio integrado de projetos. 


\section{Tabela 1.}

Perfil dos Entrevistados

\begin{tabular}{ccc}
\hline Entrevistado & Cargo do Entrevistado & Experiência no Cargo \\
\hline Entrevistado 1 & Gerente de tecnologia & 25 anos \\
Entrevistado 2 & Gerente de projetos de negócios & 10 anos \\
\hline
\end{tabular}

Fonte: Elaborada pelos autores

Inicialmente identificou-se o número de portfólios setoriais que competiam pelos mesmos recursos organizacionais, demonstrando eventuais interferências na execução do portfólio de cada unidade de negócio. Da mesma forma, o novo portfólio integrado de projetos de negócios foi caracterizado e as novas práticas constituintes do gerenciamento de portfólio foram decompostas.

A partir da caracterização das funções do novo portfólio integrado de projeto, este foi comparado com as características da estruturação do portfólio de Meskendahl (2010). Além disso, aprofundou-se a caracterização do portfólio de projetos integrado, ao identificar as categorias estratégicas escolhidas para o balanceamento do portfólio integrado. Por fim, as métricas para qualificação dos projetos em cada cesta estratégica foram destacadas.

\section{Contexto da situação problema}

A evolução do gerenciamento de portfólio para compor o portfólio integrado de projetos de negócios ocorreu num banco múltiplo brasileiro. Este banco será denominado neste trabalho como Banco A, já que seu nome não será publicado por motivo de confidencialidade. Caracteriza-se como uma sociedade anônima de capital majoritário privado, com ações listadas na bolsa de valores de São Paulo, que emprega mais de 90 mil colaboradores e tem faturamento anual na casa de 100 bilhões.

Oferece ampla carteira de produtos, desde serviços de conta corrente e financiamentos de crédito até investimentos variados. Atende clientes pessoa física e jurídica, de diferentes perfis econômicos. Logo, para suportar as necessidades dos clientes e do mercado, aprimora suas operações por meio de projetos, como estabelece documento da Federação Brasileira de Bancos (2018).

Este trabalho foi desenvolvido com foco no segmento de pessoas físicas, estruturado em 11 unidades de negócios. 1) Estratégia comercial varejo, 2) estratégia comercial elite, 3) produtos de conta corrente, incluindo crediários, 4) crédito, 5) fundos de investimentos, 6) investimentos de tesouraria, 7) seguros e capitalização, 8) previdência, 9) financiamentos de 
veículos, 10) financiamentos imobiliários e 11) cartões de crédito. Na situação inicial, cada uma das 11 unidades de negócio definia metas estratégicas independentes e contava com uma equipe autônoma de gerenciamento de projetos e portfólio que administrava cada portfólio setorial.

Nesta época a etapa de seleção e priorização dos portfólios setoriais era executada de forma intuitiva pelos executivos de cada unidade de negócio do Banco A. Tinham como base o escopo estimado para cada projeto potencial dos portfólios setoriais. Uma vez selecionada a lista de projetos setoriais, os recursos disponíveis nas unidades de tecnologia que atendiam cada unidade de negócios eram alocados aos projetos priorizados. Por exemplo, a área de crédito selecionava a lista de projetos da unidade de tecnologia de crédito e a área de contas correntes selecionava a lista de projetos da unidade de tecnologia de contas correntes.

No entanto, esta configuração não considerava que alguns projetos precisavam ser construídos por meio de parceria entre as unidades de tecnologia que atendiam mais de uma unidade de negócios. Por exemplo, projeto de crédito que criasse regra de concessão poderia envolver unidades de tecnologia de cartões de crédito e contas correntes, conforme Figura 1.

\section{Figura 1.}

\section{Configuração dos Portfólios Setoriais na Situação Inicial}

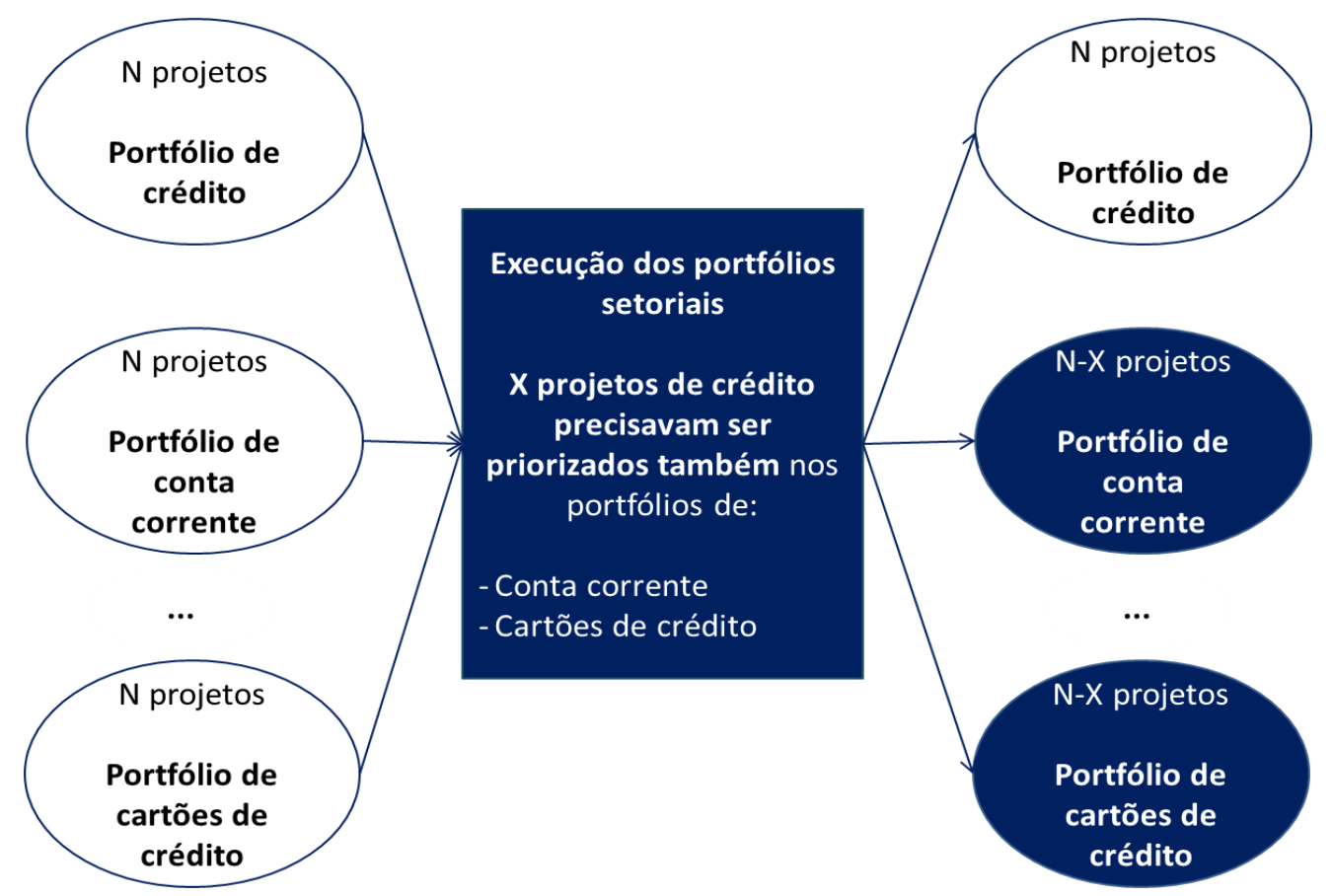

Fonte: Elaborada pelos autores. 
Nestes casos, a decisão estratégica de qual projeto priorizar, considerando as interferências entre diferentes unidades de tecnologia, era indiretamente transferida para a área de tecnologia. Segundo relatado pelo Entrevistado 1, um gerente de tecnologia que vivenciou a implantação do portfólio integrado: "Não havia uma priorização formal, já que havia muita influência 'política' dos diretores e seus subordinados. Não havia uma visão de 'o melhor para a instituição' e sim de 'o melhor para o meu resultado"”. Como dito, a falta de uma visão integrada do portfólio de projetos de negócios impedia que os portfólios setoriais fossem executados como planejado, com reflexos negativos na estratégia da organização.

\section{Tipo de intervenção e mecanismos adotados}

Para aperfeiçoar o gerenciamento do portfólio de projetos de negócios da instituição, a unidade de negócios de contas correntes foi designada para organizar uma força tarefa que atingisse os demais segmentos. A proposta era elaborar uma lista única de projetos, para que a seleção de projetos de negócios, que comporiam o portfólio se desse de maneira integrada, conforme esquema apresentado na Figura 2. Portanto, tinha como objetivo coletar as propostas de projetos das 11 unidades de negócios para definir, de forma conjunta, aquelas prioritárias para a instituição, respeitando direcionadores estratégicos pré-definidos.

Figura 2.

Aprimoramento na Seleção de Projetos de Negócio do Portfólio Integrado

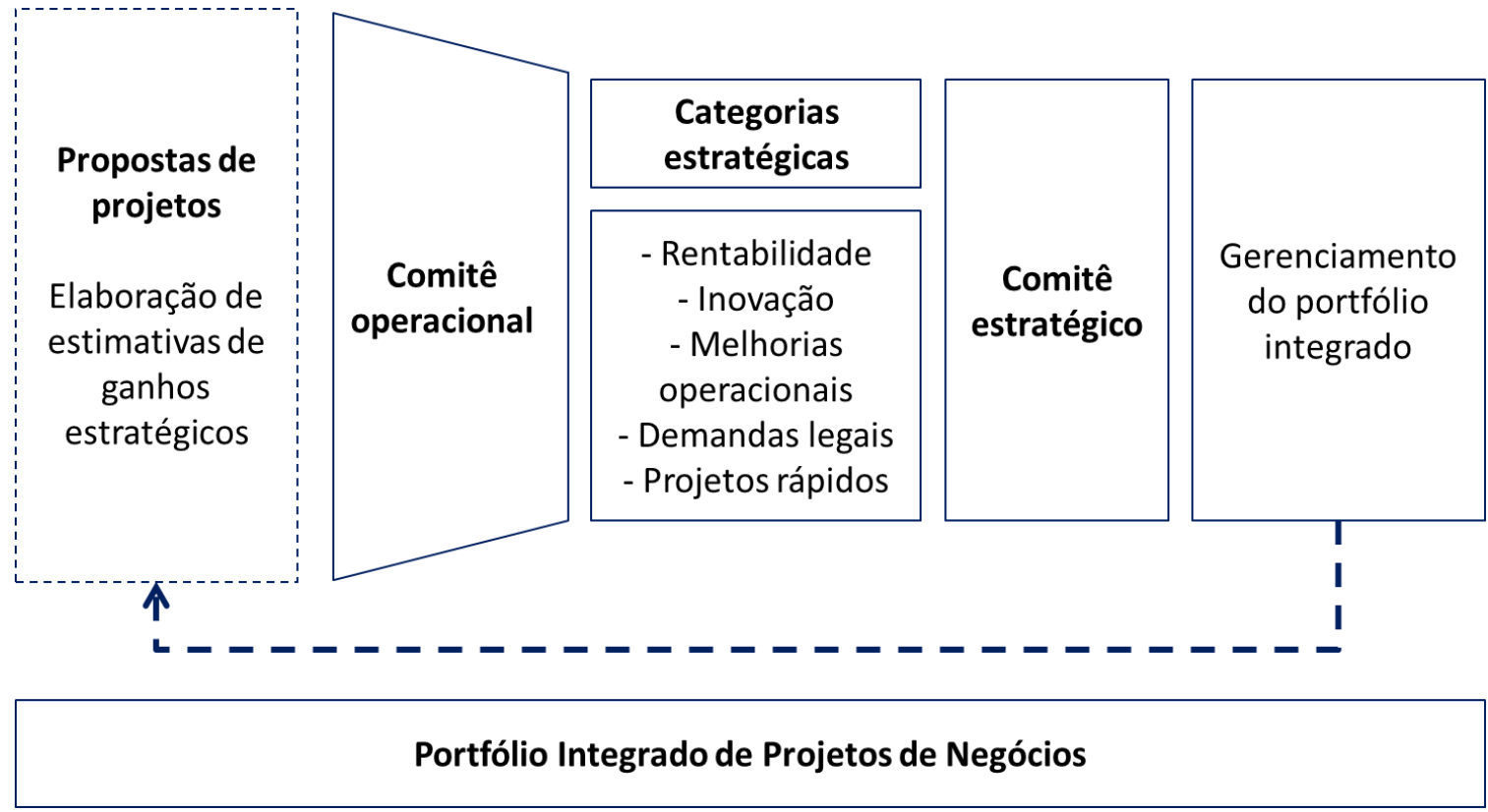

Fonte: Elaborada pelos autores. 
Nesta linha, categorias estratégicas foram propostas para balancear o portfólio de projetos, tendo em vista o alinhamento com a estratégia organizacional. As propostas de projetos eram qualificadas numa das categorias estratégicas, quais sejam: rentabilidade, melhorias operacionais, inovação, demandas legais e projetos rápidos, conforme Figura 2. Na categoria de rentabilidade, as propostas de projetos eram avaliadas com base neste indicador previsto para os próximos anos.

Por outro lado, nas categorias de melhorias operacionais e inovação, estimavam-se economia de recursos, maior produtividade operacional ou maior satisfação de clientes, entre outras variáveis. As demandas legais eram listadas com base na data em que deveriam estar implantadas, enquanto para os projetos rápidos, cada unidade de negócio priorizava seus empreendimentos com cronograma de até um mês e que pudessem ser executados sem interferência de unidades de tecnologia alheias à própria unidade de negócio.

Foi previsto que as propostas de projetos das unidades de negócios fossem discutidas em comitê operacional que aconteceria a cada trimestre. E na sequência, o portfólio integrado resultante seria ratificado por comitê estratégico institucional conforme Figura 2. Portanto, cada unidade de negócio tinha cerca de dois meses para produzir suas estimativas de ganhos para os projetos a serem discutidos nos comitês operacionais de seleção e priorização.

Esta configuração do portfólio integrado foi proposta pela unidade de contas correntes, mediante reuniões de consulta às necessidades dos demais segmentos. Foi aprovada em comitê estratégico com representantes da alta gestão, no qual foi definido também o modus operandi dos comitês operacionais do portfólio.

O entrevistado 2, gerente de projetos de negócios, caracterizou os comitês operacionais. "Somente gerentes seniores, com competência para tomada de decisão, participavam dos comitês operacionais. Além disso as decisões eram registradas em atas e acompanhadas nos comitês executivos, por meio de indicadores pré-definidos." Nestas reuniões, os gerentes exercitavam bastante suas habilidades de negociação. Já que os ganhos calculados para as propostas de projetos norteavam as decisões, mas a representatividade de cada unidade de negócio no portfólio integrado também era levada em conta.

Uma vez selecionados os projetos de negócios para integrarem o portfólio integrado, a execução do portfólio era gerenciada de forma centralizada pela equipe de projetos de contas correntes, que atuava como gestor do portfólio integrado de projetos. As equipes dos demais segmentos controlavam o andamento de seus projetos, e informavam a situação semanalmente ao escritório de gerenciamento integrado. Assim, eventuais replanejamentos eram decididos de forma unificada, podendo retroalimentar o próximo ciclo de priorização. 


\section{Resultados obtidos e análise}

O novo portfólio integrado de projetos do Banco A pode ser comparado com o modelo proposto por Meskendahl (2010), pois aprimora as características das funções de estruturação do portfólio como: a) $\mathrm{O}$ alinhamento do portfólio com a estratégia organizacional. b) A formalização dos processos de identificação, avaliação e seleção dos projetos do portfólio. c) A integração das diversas áreas corporativas na tomada de decisão do portfólio. d) E a diligência com que o portfólio era balanceado em projetos capazes de refletir objetivos de curto e longo prazo. Desta forma, a Tabela 2 estabelece relação entre cada característica da estruturação de portfólio de Meskendahl (2010) e a percepção dos entrevistados deste relato técnico.

\section{Tabela 2.}

Percepções de Entrevistados Sobre o Gerenciamento de Portfólio Integrado

\begin{tabular}{|c|c|c|}
\hline $\begin{array}{l}\text { Característica das } \\
\text { funções de estruturação } \\
\text { do portfólio }\end{array}$ & $\begin{array}{l}\text { Entrevistado 1- } \\
\text { Gerente de tecnologia }\end{array}$ & $\begin{array}{l}\text { Entrevistado } 2- \\
\text { Gerente de projetos de } \\
\text { negócios }\end{array}$ \\
\hline $\begin{array}{l}\text { Alinhamento com a } \\
\text { estratégia organizacional }\end{array}$ & $\begin{array}{l}\text { "A implantação da lista única } \\
\text { contribuiu para a realização da } \\
\text { estratégia da instituição." }\end{array}$ & $\begin{array}{l}\text { "Direcionou os } r \text { recursos } \\
\text { financeiros e esforços da Instituição } \\
\text { para suas verdadeiras prioridades, } \\
\text { evitando retrabalho e entregas } \\
\text { desnecessárias." }\end{array}$ \\
\hline $\begin{array}{l}\text { Formalização dos } \\
\text { processos de avaliação e } \\
\text { seleção de projetos }\end{array}$ & $\begin{array}{l}\text { "A formalização passou a ser } \\
\text { encarada de modo mais profissional } \\
\text { por todos os envolvidos, sejam } \\
\text { demandantes ou desenvolvedores, } \\
\text { pois qualquer problema impactaria } \\
\text { toda a fila de projetos." }\end{array}$ & $\begin{array}{l}\text { "A formalização aumentou, pois } \\
\text { era necessário que às decisões fossem } \\
\text { acessíveis a todas as unidades de } \\
\text { negócio." }\end{array}$ \\
\hline $\begin{array}{l}\text { Integração das } \\
\text { várias áreas corporativas } \\
\text { nas decisões do portfólio }\end{array}$ & $\begin{array}{l}\text { "A comunicação entre as áreas } \\
\text { solicitantes passou a ser mais } \\
\text { transparente, uma vez que } \\
\text { concorriam claramente pelos mesmos } \\
\text { recursos." }\end{array}$ & $\begin{array}{l}\text { "A interação entre as diversas } \\
\text { áreas de negócio aumentou } \\
\text { consideravelmente, pois os recursos } \\
\text { de controle e desenvolvimento dos } \\
\text { projetos eram compartilhados." }\end{array}$ \\
\hline $\begin{array}{l}\text { Balanceamento do } \\
\text { portfólio para refletir } \\
\text { objetivos de curto e longo } \\
\text { prazo }\end{array}$ & $\begin{array}{l}\text { "O planejamento passou a ser } \\
\text { efetivamente feito e executado, uma } \\
\text { vez que as mudanças deixaram de ser } \\
\text { tão constantes quanto } \\
\text { anteriormente." }\end{array}$ & $\begin{array}{l}\text { "Os projetos eram divididos em } \\
\text { categorias estratégicas, seguindo um } \\
\text { percentual pré-definido de acordo } \\
\text { com as diretrizes da organização." }\end{array}$ \\
\hline
\end{tabular}

Fonte: Elaborada pelos autores.

Com base nas informações coletadas, é possível afirmar que a implantação do portfólio integrado de projetos de negócios permitiu maior alinhamento deste com a estratégia organizacional. Notadamente, houve aprimoramento na formalização dos processos de 
identificação, avaliação e seleção dos projetos do portfólio, tornando-os transparentes para todas as unidades de negócios envolvidas. Além disso, a formação dos comitês operacional e estratégico de priorização do portfólio promoveu a integração das diversas áreas corporativas e permitiu melhor balanceamento do portfólio ao organizá-lo em categorias estratégicas de curto e longo prazo.

Portanto, a implantação do portfólio integrado de projetos, por meio da definição de processos institucionais de gerenciamento do portfólio, aprimora seu gerenciamento. Consequentemente, aperfeiçoa a atuação do portfólio como instrumento da estratégia organizacional, favorecendo o atingimento dos objetivos estratégicos organizacionais, conforme estabelece Bredillet et al. (2018).

Como contribuição para a prática profissional, este relato retrata processos institucionais de gerenciamento do portfólio de projetos, que podem ser tomados como benchmark por outras organizações. Apresenta ainda informações acerca dos direcionadores estratégicos para balanceamento do portfólio de uma instituição financeira, os quais refletem equilíbrio entre as estratégias de curto e longo prazo. Do ponto de vista acadêmico, contribui com a literatura de gerenciamento de portfólio de projetos, retratando estudo de caso real, no qual são verificados os conceitos teóricos das funções de estruturação do portfólio de Meskendahl (2010).

\section{Conclusão}

Este trabalho atingiu o objetivo proposto, uma vez que apresentou como uma instituição bancária integrou seus vários portfólios de projetos setoriais, por meio da implementação de processos institucionais de gerenciamento de portfólio que favorecem o atingimento dos objetivos estratégicos organizacionais. Para isso, o gerenciamento de portfólio do Banco A foi caracterizado, por meio de entrevistas, análise documental e observação do pesquisador. Enquanto na etapa inicial vários portfólios setoriais menos estruturados coexistiam e competiam entre si, na etapa final estabelecia-se o portfólio integrado de projetos de negócios.

Com base na pesquisa empreendida, verifica-se que a implantação do portfólio integrado de projetos permitiu maior alinhamento deste com a estratégia organizacional. Os processos de identificação, avaliação e seleção de projetos foram formalizados e aprimorados. Em linha, comitês operacionais e estratégicos de portfólio facilitaram a integração das diversas unidades de negócios corporativas, contribuindo para a transparência das decisões organizacionais. Ademais, o estabelecimento de categorias estratégicas de curto e longo prazo permitiram melhor balanceamento do portfólio. 
Demonstra-se, portanto, que o modelo de gerenciamento de portfólio da instituição foi aperfeiçoado como um todo. Como contribuição prática, os benefícios de um portfólio integrado de projetos, retratados para o Banco A, podem inspirar instituições interessadas em aprimorar seus mecanismos de gestão estratégica e de gerenciamento de projetos.

Entretanto, alguns aspectos limitaram a profundidade dos resultados atingidos, como em qualquer trabalho científico. Como limitação principal, cita-se a dificuldade na obtenção de dados quantitativos para caracterizar a eficácia do portfólio integrado frente à situação inicial. Neste sentido, como sugestão para estudos futuros está a caracterização quantitativa de como as melhorias do gerenciamento do portfólio se refletem no resultado das organizações. Da mesma forma, outros estudos que caracterizem a configuração do gerenciamento de portfólio em outras organizações, dentro e fora da indústria de serviços, contribuiriam para o conhecimento acerca destes processos organizacionais.

\section{Referências}

Aas, T. H., Breunig, J., \& Hydle, K. M. (2017). Exploring new service portfolio management. International Journal of Innovation Management, 21(06), 1750044.

Archer, N. P., \& Ghasemzadeh, F. (1999). An integrated framework for project portfolio selection. International Journal of Project Management, 17(4), 207-216. https://doi.org/10.1016/S0263-7863(98)00032-5

Biancolino, C. A., Kniess, C. T., Maccari, E. A., \& Rabechini, R. Jr. (2012). Protocolo para Elaboração de Relatos de Produção Técnica. Revista de Gestão e Projetos - GeP, 3(2), 294-307. https://doi.org/10.5585/10.5585

Bredillet, C., Tywoniak, S., \& Tootoonchy, M. (2018). Exploring the dynamics of project management office and portfolio management co-evolution: A routine lens. International Journal of Project Management, 36(1), 27-42. https://doi.org/10.1016/j.ijproman.2017.04.017

Carvalho, M. M. de, Lopes, P. V. B. V. L., \& Marzagão, D. S. L. (2013). Project portfolio management: Trends and contributions of literature. Gestão e Produção, 20(2), 433454. https://doi.org/10.1590/S0104-530X2013000200013

Creswell, J. W., \& Creswell, J. D. (2017). Research Design: Qualitative, Quantitative, and Mixed Methods Approaches. SAGE Publications.

FEBRABAN, F. B. de. (2018). Pesquisa FEBRABAN de Tecnologia Bancária. https://portal.febraban.org.br:443/pagina/3106/48/pt-br/pesquisa

Hopmere, M., Crawford, L., \& Harré, M. S. (2020). Proactively Monitoring Large Project Portfolios. Project Management Journal, 51(6), 656-669. https://doi.org/10.1177/8756972820933446 
Löwstedt, M., Räisänen, C., \& Leiringer, R. (2018). Doing strategy in project-based organizations: Actors and patterns of action. International Journal of Project Management, 36(6), 889-898. https://doi.org/10.1016/j.ijproman.2018.05.002

Meskendahl, S. (2010). The influence of business strategy on project portfolio management and its success-A conceptual framework. International Journal of Project Management, 28(8), 807-817. https://doi.org/10.1016/j.ijproman.2010.06.007

Padovani, M., \& Carvalho, M. M. (2016). Integrated PPM Process: Scale Development and Validation. International Journal of Project Management, 34(4), 627-642. https://doi.org/10.1016/j.ijproman.2016.01.006

Paiva, D. C., \& Rabechini Jr., R. (2020). Evolução do Gerenciamento de Portfólio em um Banco: Novos processos e competências. VIII Singep - Simpósio Internacional de Gestão de Projetos, Inovação e Sustentabilidade, 14.

PMI. (2017). Um Guia do Conhecimento em Gerenciamento de Projetos (Guia PMBOK®) $6^{a}$ edição (Edição: 6a). Project Management Institute.

Wheelwright, S. C., \& Clark, K. B. (1992). Creating project plans to focus product development. Harvard Business Review, 70(2), 70-82.

World Development Indicators | The World Bank. (2019). http://wdi.worldbank.org/table/4.2

Yin, R. K. (2017). Case Study Research and Applications: Design and Methods (Sixth Edition). SAGE Publications, Inc. 